\title{
Layer by Layer Segmentation of Water Distribution from Neutron Imaging of Large Scale Cells
}

\author{
Pierre Boillat, ${ }^{\mathrm{a}, \mathrm{b}, \mathrm{z}}$ Alfredo Iranzo, ${ }^{\mathrm{c}}$ and Johannes Biesdorf ${ }^{\mathrm{a}}$ \\ ${ }^{a}$ Electrochemistry Laboratory (LEC), Paul Scherrer Institut (PSI), 5232 Villigen, Switzerland \\ ${ }^{b}$ Neutron Imaging and Activation Group (NIAG), Paul Scherrer Institut (PSI), 5232 Villigen, Switzerland \\ ${ }^{c}$ AICIA, School of Engineering, Sevilla, Spain
}

\begin{abstract}
We present a method for distinguishing liquid water content in the different layers of a polymer electrolyte fuel cell ("anode flow channels", "cathode flow channels", and "GDL/MEA") from through-plane neutron imaging. The method is based on sudden decompression of the anode and cathode sides of a cell in two separate steps. The decompression induces a strong purging effect with effective liquid water removal from the flow channels, without affecting the gas diffusion layers (GDL) and membrane electrode assembly (MEA). The water in the flow channels is imaged by the differences of water distribution before and after the corresponding purges, and the water remaining after the purges is considered to be GDL/MEA water. The method is valid both for qualitative and quantitative analysis. A validation of the method is presented in this work, including results obtained for a $50 \mathrm{~cm}^{2} \mathrm{commercial} \mathrm{PEFC}$. (C) The Author(s) 2015. Published by ECS. This is an open access article distributed under the terms of the Creative Commons Attribution Non-Commercial No Derivatives 4.0 License (CC BY-NC-ND, http://creativecommons.org/licenses/by-nc-nd/4.0/), which permits non-commercial reuse, distribution, and reproduction in any medium, provided the original work is not changed in any way and is properly cited. For permission for commercial reuse, please email: oa@electrochem.org. [DOI: 10.1149/2.0511506jes] All rights reserved.
\end{abstract}

Manuscript submitted December 12, 2014; revised manuscript received February 20, 2015. Published March 5, 2015.

Neutron imaging is a powerful instrument for the research and development of polymer electrolyte fuel cells (PEFCs), as it allows the visualization and quantification of the local water content within the cell. Liquid water is particularly present at the cathode side, and can result in mass transport losses and restrict the operation at high current densities. ${ }^{1,2}$ Also, either an excess of liquid water or a dryout of the membrane can result in significant durability issues. ${ }^{3,4}$ Therefore, in order to ensure a successful operation of the cell an appropriate water balance must be achieved, which is the objective of many studies available in the literature, both experimental ${ }^{5-7}$ and by means of modelling. ${ }^{8-10}$ However, when performing neutron imaging in through-plane direction (beam axis perpendicular to the cell membrane), water content in the anode and cathode sides superpose themselves in the image and it is not possible to distinguish the liquid water distribution in both sides of the cell. In case that liquid water is present in the flow field channels as well, the interpretation of the results may be even more complicated. A possibility to obtain full access to the water distribution across the cell structure is to use inplane imaging (beam axis parallel to the membrane), which received considerable attention is the last years ${ }^{7,11-15}$ and has been a strong driving force to improve the spatial resolution of neutron imaging. However, in plane imaging introduces a limitation of the active area size of approximately $20 \mathrm{~mm}$ in the beam direction, and is not suited for all fuel cells designs. In this context, a method for qualitatively and quantitatively enable the differentiation of the liquid water distributions in the different layers of the cell from through-plane imaging is of high interest. As we previously reported, ${ }^{16}$ some distinctions are possible using the differences of morphology between water in the gas diffusion layers and in the channels, but such an approach is limited by the necessity of having a resolution high enough to observe such differences (which is not the case when imaging large cells), and will only work for certain types of water accumulations. Furthermore, In some studies, ${ }^{6,17,18}$ the specific designs of anode and cathode flow channels were taken as an advantage for a distinction between water accumulations in the anode and cathode channels. However, this way of doing remains essentially qualitative and is limited to sections of the flow field where the anode and cathode channels do not overlap. However, such an approach is limited to specifi flow field designs and does not yield quantitative information. The method presented here is based on a sudden decompression of the anode and cathode sides of a cell performed in two separate steps. The sudden decompression induces a strong purging effect of the channels with effective liquid water removal, without affecting the water in the membrane electrodes assembly (MEA) and in the gas diffusion layers (GDLs). Some studies have been reported on the purging of water after cell shutdown, analyzed either by means of imaging ${ }^{19}$ or by observing the evolution of the high frequency resistance. ${ }^{20}$ In particular, Owejan et al..$^{19}$ reported that the water in flow channels is effectively removed by sudden pressure removal. The same authors have also shown, by mounting water saturated GDLs either on the anode or cathode side and subsequently flowing dry gas on the cathode side, that the removal of GDL water by evaporation is partially limited by the transfer through the membrane. While these studies had as a primary goal the optimization of purge strategies at cell shutdown, we can use the effects observed to derive a methodology to segment the water observed in the operating cell in different layers. The clear effect of decompression allows segmentation between the flow channels on either side and the remaining water composed of both GDLs and the MEA. A further distinction between the GDLs and the MEA might be possible by selective evaporation from one or the other side as suggested by the work of Owejan et al. ${ }^{19}$ However, such an approach would require a more complex model based analysis clearly less robust than the simple method presented here. Thus, we will restrict us here to a distinction between three different layers: the anode flow channels, the cathode flow channels, and the remaining water (GDL and MEA). We present here a qualitative and quantitative evaluation of the method on a $50 \mathrm{~cm}^{2}$ commercial PEFC. This cell has the particularity of using a cross-flow configuration (anode channels are horizontal and cathode channels are vertical), allowing to check easily the consistence of the results.

\section{Experimental}

Cell hardware.- The cell used in the experiment was a $50 \mathrm{~cm}^{2}$ active area cell from ElectroChem Inc., with metallic Bipolar Plates (five-channel serpentine flow field). The Bipolar Plates layout is crossflow, with horizontal channels in the anode and vertical channels in the cathode. A set of Gas Diffusion Layers from SGL Group (Sigracet 24BC) were used. The GDL contains 5\% of PTFE and a Micro Porous Layer (MPL) for enhanced performance of the GDL-catalyst layer interface. A Catalyst Coated Membrane (CCM) from Baltic Fuel Cells was used, with catalyst loading at the anode and cathode electrodes of $0.3 \mathrm{mg} \mathrm{Pt} / \mathrm{cm}^{2}$ and $0.6 \mathrm{mg} \mathrm{Pt} / \mathrm{cm}^{2}$ respectively. The membrane material is Nafion- 117 .

Experimental procedure.- The NEUTRA ${ }^{21}$ beam-line at the SINQ spallation source of PSI was used for the neutron imaging experiments. An exposure time of 10 seconds was chosen. Before starting 
any test the cell was dried out flowing dry nitrogen through the anode and cathode. Then the cell operation was performed in galvanostatic mode, setting the anode and cathode flows and relative humidity to the desired conditions (a matrix of HR anode/cathode conditions was tested). The cell was operated at $2.0 \mathrm{bar}_{\text {abs }}$ and $60^{\circ} \mathrm{C}$. Cell current density, voltage, high frequency resistance (HFR) at $5 \mathrm{kHz}$, and neutron images were recorded during the entire operation. Once steady-state operation was achieved for each condition, the anode compartment was depressurized (2.0 bar to 1.0 bar) so that liquid water in anode channels was flushed out of the cell. The cathode compartment was depressurized 60 seconds later to purge the cathode channels, and the cell was maintained in such condition during 240 seconds. Images were recorded during the entire process, and the current production and gas flows were not interrupted during this operation. Within the purge sequence, 5 specific moments were defined which are used as a base for the image analysis: ${ }^{1}$ Before the anode purge ${ }^{2}$ After the anode purge $;{ }^{3}$ Before the cathode purge $;{ }^{4}$ After the cathode purge $;{ }^{5}$ At the end of the 240 seconds following the cathode purge. The water disappearing in the purge steps (between stages 1 and 2 and between stages 3 and 4) is considered to be water present in the flow channels, and the water remaining after the purge is considered to be water present in the MEA and in the GDL.

Validation experiment.- In order to perform a validation of the method by checking that the purge process did not affect the water in the GDL and MEA, the decompression approach was used in a specific operation mode of the cell. We targeted to produce a uniform distribution of water in both the MEA and GDL without having water in the flow channels. First, the cell was fully dried out by flowing dry nitrogen through the cell at $60^{\circ} \mathrm{C}$ and $2 \mathrm{bar}_{\mathrm{abs}}$. After this, the membrane was conditioned by flowing $\mathrm{H}_{2}$ in the anode $(250 \mathrm{nmL} / \mathrm{min})$ and $\mathrm{O}_{2}$ in the cathode $(1000 \mathrm{nmL} / \mathrm{min})$ at $90 \%$ relative humidity. Once the HFR reached a constant value, the gas flows were stopped, and a fixed and known quantity of water was generated uniformly in the cell active area by operating the cell at 2 A during 20 minutes. This corresponds to a quantity of water of $224 \mu \mathrm{L}$, and an average thickness of $44.8 \mu \mathrm{m}$ over the cell area. Then the cell was kept without current and gas flow and the decompression method as described previously was performed (anode purge, $60 \mathrm{~s}$ wait, cathode purge, $240 \mathrm{~s}$ wait).

Image processing.- After performing the necessary corrections (detector background, change of beam intensity, neutrons scattered by the setup), the radiograms were referenced pixel-wise by dividing the obtained image by a reference image of the dry cell before operation (dry cell is depicted in Figure 1). Therefore the attenuation corresponding to water only is obtained. When quantitative results are used, the thickness of water $\delta_{w}$ is calculated from the relative neutron transmission $\left(I / I_{0}\right)$ by inverting the Lambert-Beer law:

$$
\delta_{w}=-\ln \left(I / I_{0}\right) / \Sigma
$$

where $\sum$ is the attenuation coefficient of neutrons in liquid water, with a value of $3.5 \mathrm{~cm}^{-1}$ for the given setup, $I$ is the pixel intensity in the operation imaging and $I_{0}$ is the pixel intensity in the reference image. For the relatively low thicknesses of water in through-plane imaging, we assumed that beam hardening effects were negligible. Due to the logarithmic relation in the Lambert-Beer relation, the "differential images" reported in this work were computed by dividing pixel-wise the images to be compared.

\section{Results and Discussion}

Validation experiment.- The image sequence of the entire purge process as well as the HFR values during this process are shown in Figure 2. As seen in the image of stage 1, there is water present in the outlet portion of the anode, which was not targeted in this validation experiment. Nevertheless, a sufficient area of the cell is in the desired state for the validation: a significant amount of water in the GDL/MEA and no water in the channels. The evolution of the HFR values as well as the images show that the anode and cathode purging (during 60 and

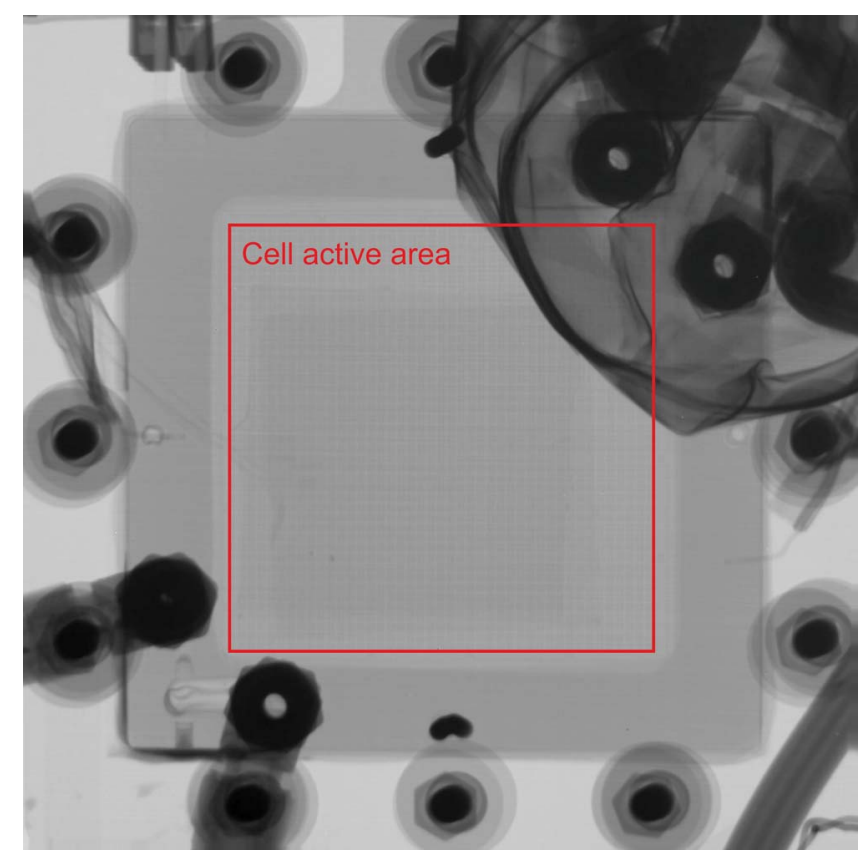

Figure 1. Radiogram of the dry cell structure.

240 s respectively) does not affect the water content in the MEA. The liquid water formed in the anode channels during the cell operation before the purging (Figure 2, stage 1) is flushed out during the anode purge, without affecting the HFR value to a large extent.

Results with cell operation.- After this initial verification, the method was used for different operating conditions, as reported in another publication. ${ }^{22}$ Here, we will analyze these results on the method point of view, based on a selected set of conditions at low and high humidity. Additionally to the radiograms, the evolution of the cell resistance (HFR) for the different conditions was analyzed, as the cell resistance is a direct indicator of the membrane water content. ${ }^{20}$ Using these two indicators (radiograms and resistance), we could assess whether our expectation that the purging process does not affect the GDL/MEA water is correct. In terms of HFR evolution during purging two different types of results were obtained. As shown in Figure 3, an increase of resistance during the purge process is clearly visible in dry conditions, while the resistance is stable during the purge in conditions with higher humidity. In the experiment represented in Figure 3, a matrix of $3 \times 3$ combinations of relative humidity were tested, each of them followed by the purge method described in the experimental section. There is a clear correlation between the humidification of the membrane (HFR) and the amount by which the HFR increases during the purge. As a representative set of the different behaviors observed in terms of HFR evolution, a more detail analysis will be presented for the selected conditions of the experiments highlighted in Figure 3. The selected cases correspond to the first and seventh condition of the complete experiment and are representative of conditions with low and high humidity values, respectively. The first condition has a low cathode relative humidity $(35 \%)$ and a significant increase of HFR during the purge, and the second experiment stage has a higher cathode relative humidity $(90 \%)$ and a constant HFR value during the purge. The results for air operation and low humidity are shown in Figure 4, where we can clearly see the evacuation of the water slugs from the cathode channels during corresponding purge (between stages 3 and 4). The evolution of the HFR value shows that the major part of the drying occurs during the 240 seconds of low pressure operation following the cathode purge (i.e. between stages 4 and 5). Only very slight HFR variations are seen during the decompression itself (i.e. between stages 1 and 2 and between stages 3 and 4) or during the $60 \mathrm{~s}$ between the purges. We can thus conclude that 

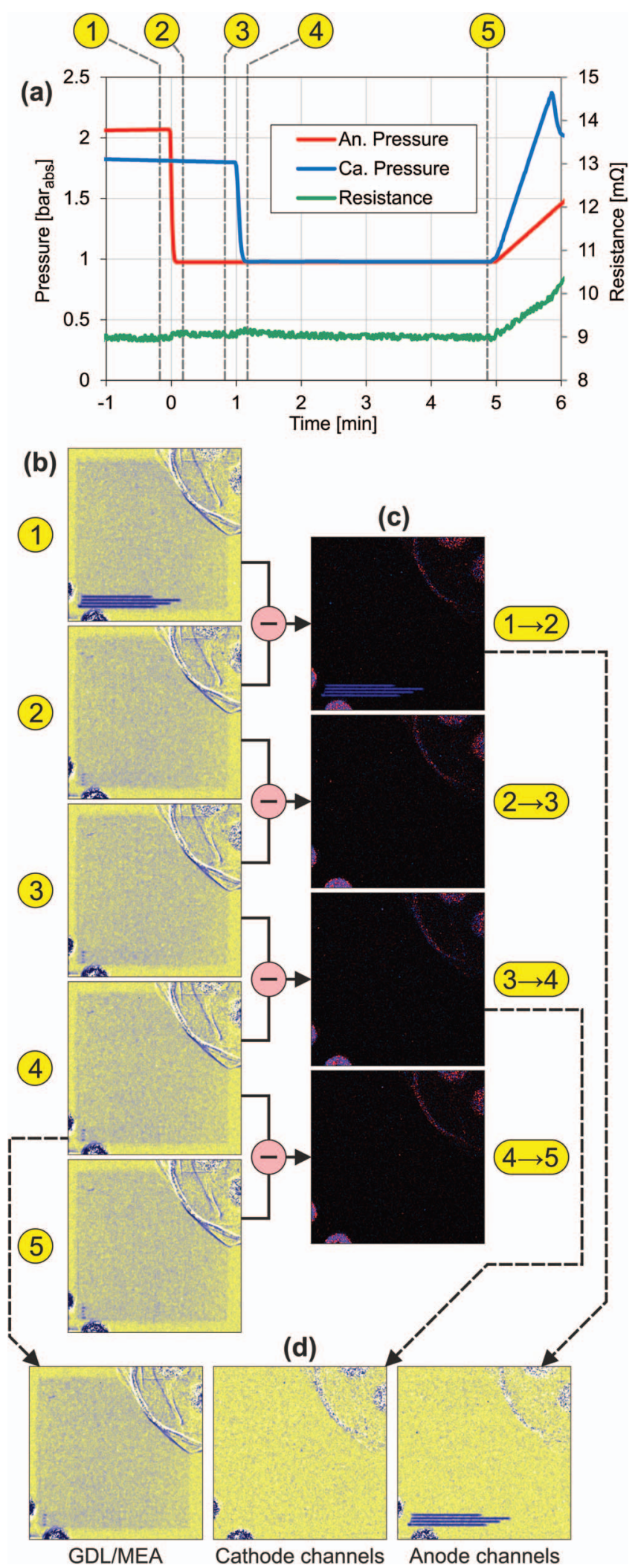

Figure 2. Evolution of the water distribution during the purge process (validation experiment). (a) Evolution of pressure and high frequency resistance. (b) Radiograms of water distribution at the five defined stages. (c) Differential radiograms between each two successive stages. (d) Corresponding distribution of water between the layers.
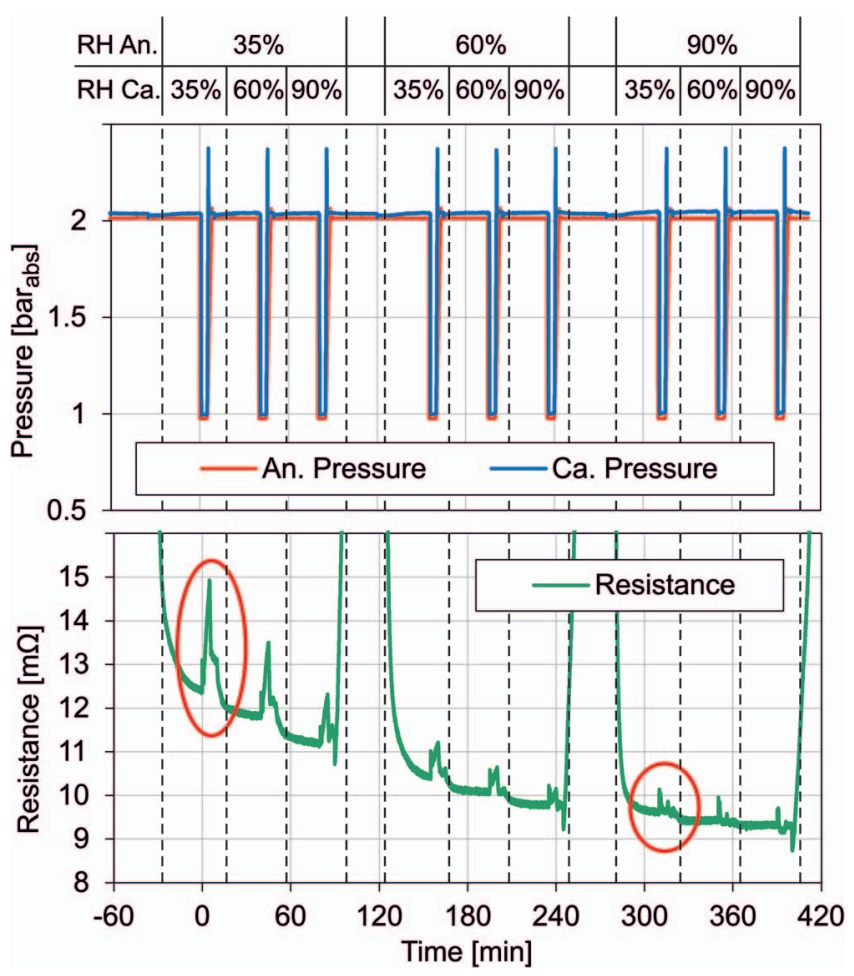

Figure 3. Evolution of the high frequency resistance (HFR) during an experiment comprising nine combinations of relative humidity for the anode and cathode and including the described purge process at the end of each operating condition. Operation with $\mathrm{H}_{2}$ in the anode and air in the cathode.

the observed drying is not primarily caused by the high flow during decompression, but by the following operation at low pressure. This result is easily explainable: because we keep the same stoichiometries throughout the purge process, the volume flow is increased at low pressure. The amount of water a partially humidified gas flow gas take as vapor being a function of the volume flow (and not of the mass flow), this logically results in higher water removal and drying of the cell. It must be noted that the flows during the purge were different for anode and cathode $(140 \mathrm{NmL} / \mathrm{min}$ for anode and $580 \mathrm{NmL} / \mathrm{min}$ for the cathode) thus providing a larger effect for the period where the cathode is not pressurized. This can explain the absence of dry out between the purges. The progressive dry-out after the cathode decompression is also observed in the neutron images (Figure 4), where less water is measured at the end of the $240 \mathrm{~s}$ of low pressure operation (stage 5) than at its beginning (stage 4). In Figure 5, we present the same analysis for air operation with high humidity. Again, cathode decompression effectively removes the liquid water from the cathode channels. Although there is no water in the anode channels (in this cell having a cross-flow configuration, it is easy to distinguish anode and cathode water slugs), we see some changes during the anode purge: small amounts of water disappear in some regions (Figure 5c, blue droplets) and appear in other regions (Figure 5c, red droplets). This can either be due to natural movements of water slugs in the cathode channels, or an indirect result of the anode decompression process. In any of these cases, this effect represents a source of error in the segmentation between layers proposed by our method, but its magnitude is very low compared to the total amount of water in the cell. As previously mentioned, the cell resistance is not varying during the purging for this condition. We can explain this by the fact that, at higher humidity, the capacity of the gas flow for water removal is lower. We even observe the opposite effect: water starts to accumulate again in the channels during the 240 seconds following the cathode purge (Figure 5, stages 4 and 5). As a final example, we present in Figure 6 the case of $\mathrm{H}_{2} / \mathrm{O}_{2}$ operation at $15 \mathrm{~A}$ with high humidity. In this case, we can observe that a small quantity of water accumulated 

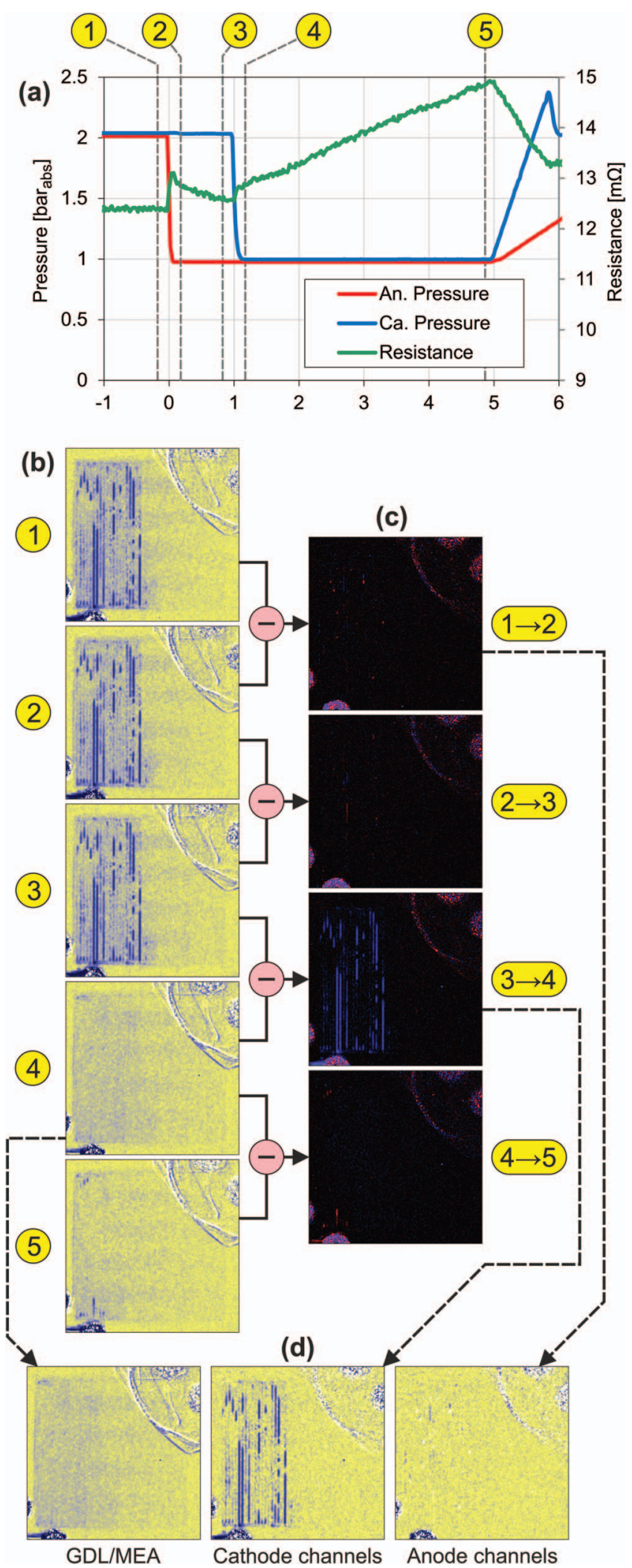

Figure 4. $\mathrm{H}_{2}$ /Air operation at $10 \mathrm{~A}$ and low humidity: evolution during the purge process. (a) Evolution of pressure and high frequency resistance. (b) Radiograms of water distribution at the five defined stages. (c) Differential radiograms between each two successive stages. (d) Corresponding distribution of water between the layers.
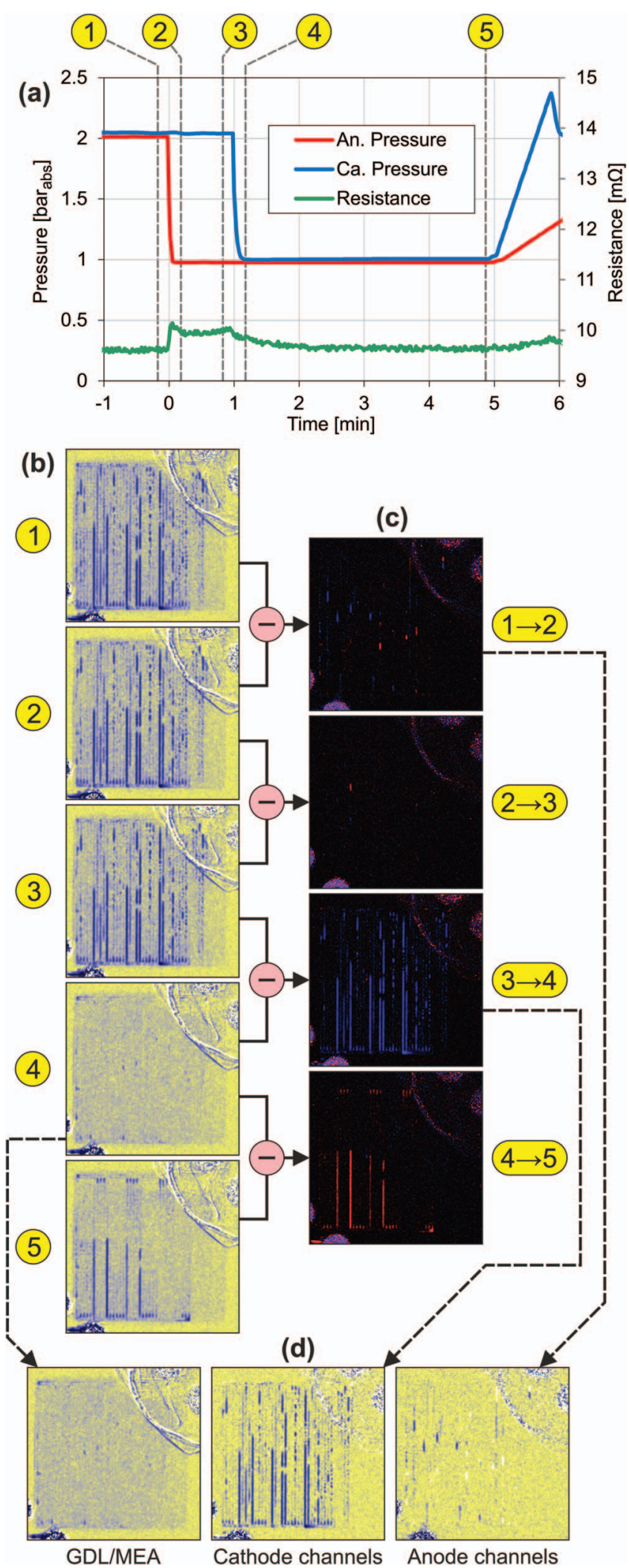

Figure 5. $\mathrm{H}_{2}$ /Air operation at $10 \mathrm{~A}$ and high humidity: evolution during the purge process. (a) Evolution of pressure and high frequency resistance. (b) Radiograms of water distribution at the five defined stages. (c) Differential radiograms between each two successive stages. (d) Corresponding distribution of water between the layers. 

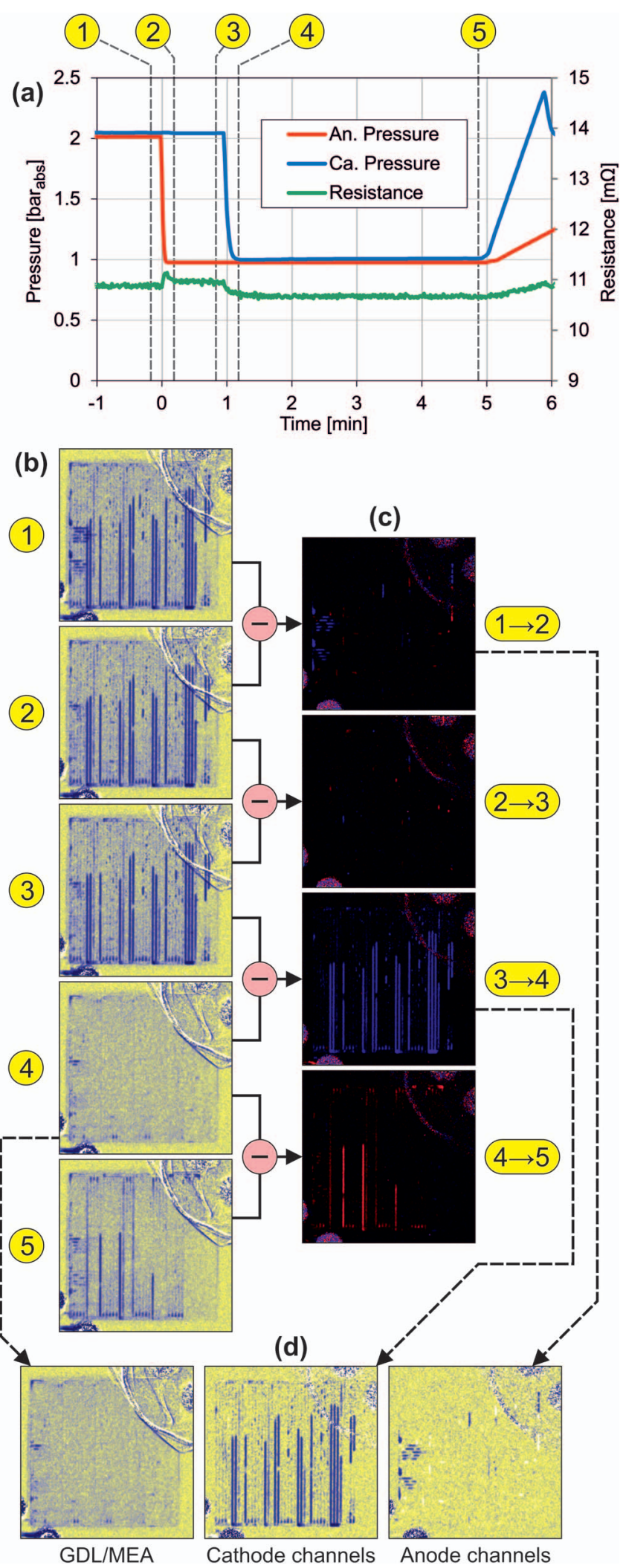

Figure 6. $\mathrm{H}_{2} / \mathrm{O}_{2}$ operation at $15 \mathrm{~A}$ and high humidity: evolution during the purge process. (a) Evolution of pressure and high frequency resistance. (b) Radiograms of water distribution at the five defined stages. (c) Differential radiograms between each two successive stages. (d) Corresponding distribution of water between the layers.

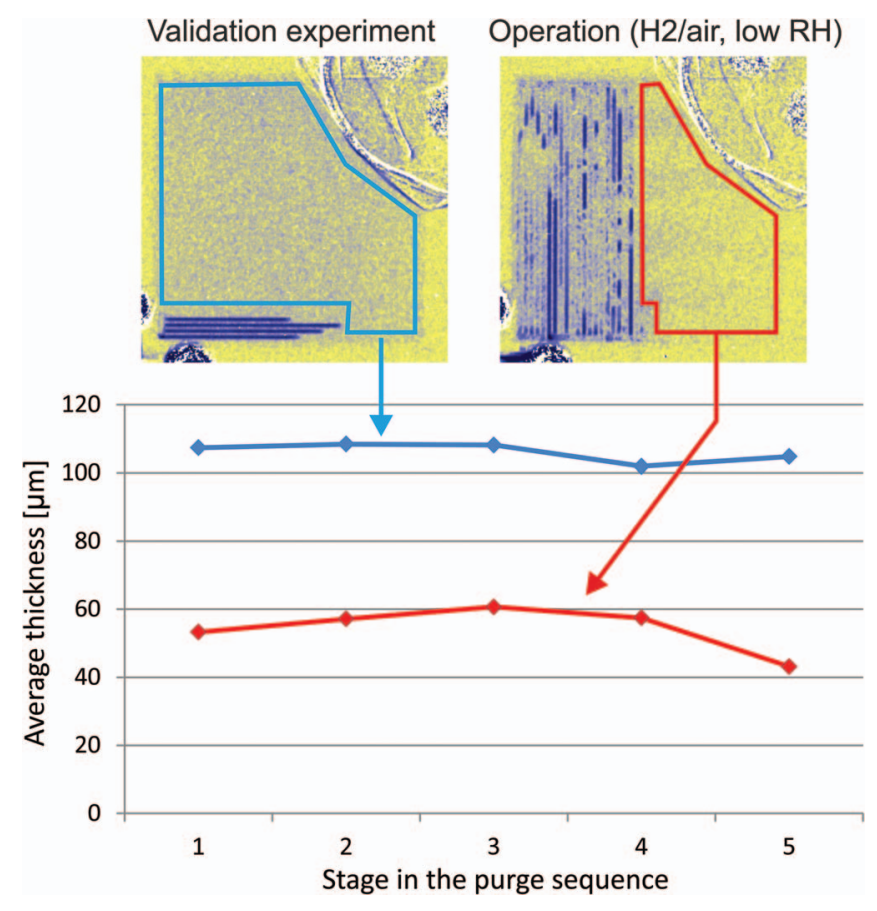

Figure 7. Average thickness of water at the five different stages of the purging process in the regions having no water in the flow channels.

in the anode flow channels during operation (horizontal slugs). Most of this water is effectively removed during the anode decompression, and thus we can observe in Figure 6 the results of a condition where water is present in the three separated layers. In this case, liquid water is present in both anode and cathode channels (horizontal and vertical strips in Figure 6, image 1). Both are however effectively and separately removed when the purging method is applied as observed in the neutron image sequence in Figure 6.

Quantification.- In order to verify the influence of the purging process in a quantitative manner, the average water thickness at the five stages of the decompression/purging process was calculated for regions having no water in the flow channels. The quantitative results are presented in Figure 7, where we can observe that the variations during the purge process are reasonably small - with the notable exception of the dry-out process between stages 4 and 5 for the dry conditions, as already observed from the HFR. We can notice that the measured thickness of water in the validation experiment is significantly higher than the $45 \mu \mathrm{m}$ of water produced. This is due to the initial accumulation of water in the membrane equilibration step. The average thickness measured by neutron imaging before the current generation was $60-65 \mu \mathrm{m}$ and the sum of this value plus the produced water is consistent with the thickness measured after generation.

Discussion of the results. - The water evolution in the four minutes following the purge is different for low and high humidity conditions: in the first case, the cell dries out when operated at low pressure, and in the second case water accumulates back in the cell during this time. The balance between water production and water removal by evaporation depends on the pressure, temperature and magnitude of the gas flows, but also obviously on the relative humidity of the incoming flow. The difference in cathode humidity between these conditions changes the balance between dry-out and water accumulation. Nevertheless, the same conclusion can be drawn for both cases: the image representative of water distribution after the purges has to be taken as fast as possible after the cathode decompression. If the image quality is sufficient for using relatively short exposure times, the evolution of water content after cathode decompression (between phases 4 and 5 in our experiments) is not disturbing because the image at stage 5 is 
not used for the final result. The impact of cathode decompression on the humidity level was observed to be stronger than that of the anode, which can be explained by the difference in gas flow magnitudes. This result justifies a posteriori our choice of depressurizing the anode before the cathode. The most disturbing effect is that, as observed in Figure 5 and Figure 6, variations at the cathode side occurring during the anode depressurization induce a small error in the segmentation process. Unlike the case of real purging of water, where water is only removed, these variations are typically visible as movements: water disappears from some positions and appears at other positions. Therefore, a careful observation of the differential images is sufficient for avoiding erroneous interpretations. All in all, the results obtained in these experiments indicate that the use of the purging method is a very effective way to perform a basic segmentation of water between the GDL/MEA layer and the flow channels on anode and cathode sides. A few improvements can still be proposed. To avoid perturbations due to natural movements of water slugs, a possibility is to interrupt the gas flows and current production before the purge. A possible drawback of this way of performing the purge is that the balance between electro-osmotic drag and back-transport of water will be disturbed, and that the water might re-distribute between the layers in this case. The best solution is probably to further reduce the time between the images acquired just before and just after a purge. This could be done, for example, by synchronizing the purge protocol with the image acquisition system, so that the decompression occurs exactly between two radiograms. Finally, one drawback of the method is that a relatively large pressure differential between anode and cathode (1 bar in this case) is generated, which could be damaging in the case of thin membranes. To solve this, a possibility would be to reduce the magnitude of the decompression, for example to 0.5 bars below the operating pressure. This would have the further advantage to extend the parameter range available for this method to lower initial pressures. As the purge process was observed to be very efficient in this work, there is a good probability that a partial decompression would be sufficient. A last point worth noting is that the flushing of droplets from the flow channels might be linked to the removal of GDL water directly connected to this droplet, as suggested in the literature, ${ }^{23}$ and that this might induce an underestimation of the GDL water content with our method. The observation of the radiograms (for example from Figure 5) do not show such an effect, which would appear as a lower GDL water content in the places where liquid water was present in the channel. The possible explanation is that the part of GDL water which is easily removed by the droplets does not constitute an important portion of the total GDL water, and we can conclude that this effect should not affect our measurement significantly.

\section{Conclusions}

A method for distinguishing liquid water content in different layers of a polymer electrolyte fuel cell (anode channels, cathode channels, and GDL/MEA) from through-plane neutron imaging (beam perpendicular to the membrane) was successfully experimented. The approach consists of successive sudden decompression of anode and cathode sides of the cell. The method is valid both for qualitative and quantitative analysis, as was shown by the results obtained using a 50 $\mathrm{cm}^{2}$ commercial PEFC. The results show that the use of this purging method is able to effectively remove the liquid water from the anode and cathode channels in separate steps, and therefore enables to distinguishing the water content in the different cell layers. In the minutes following the decompression, the cell either dries out, or water accumulates back, depending on the operating conditions and in particular on the relative humidity of the cathode gas flow. Nevertheless, by using radiograms measured closely after the removal of pressure, a good segmentation of water between the layers is obtained.

\section{Acknowledgments}

This work was carried out with the support of the European Community. We appreciate the support of the European Research Infrastructure project "H2FC European Infrastructure" (funded under the FP7 specific programme Capacities, grant agreement Number FP7284522).

Alfredo Iranzo also gratefully acknowledges the support of the Spanish Ministry of Economy and Competitiveness under the program INNCORPORA, Torres-Quevedo PTQ-11-04703.

\section{References}

1. H. Li, Y. H. Tang, Z. W. Wang, Z. Shi, S. H. Wu, D. T. Song, J. L. Zhang, K. Fatih, J. J. Zhang, H. J. Wang, Z. S. Liu, R. Abouatallah, and A. Mazza, J Power Sources, 178, 103 (2008)

2. W. Dai, H. J. Wang, X. Z. Yuan, J. J. Martin, D. J. Yang, J. L. Qiao, and J. X. Ma, Int J Hydrogen Energ, 34, 9461 (2009).

3. J. F. Wu, X. Z. Yuan, J. J. Martin, H. J. Wang, J. J. Zhang, J. Shen, S. H. Wu, and W. Merida, J Power Sources, 184, 104 (2008).

4. W. Schmittinger and A. Vahidi, J Power Sources, 180, 1 (2008).

5. S. Tsushima and S. Hirai, Prog Energ Combust, 37, 204 (2011).

6. J. P. Owejan, J. J. Gagliardo, J. M. Sergi, S. G. Kandlikar, and T. A. Trabold, Int J Hydrogen Energ, 34, 3436 (2009).

7. P. Boillat, P. Oberholzer, A. Kaestner, R. Siegrist, E. H. Lehmann, G. G. Scherer, and A. Wokaun, Journal of the Electrochemical Society, 159, F210 (2012).

8. C. Y. Wang, Chem Rev, 104, 4727 (2004).

9. S. Um and C. Y. Wang, J Power Sources, 156, 211 (2006).

10. S. Shimpalee, S. Greenway, D. Spuckler, and J. W. Van Zee, J Power Sources, 135, 79 (2004)

11. R. Yasuda, K. Nittoh, C. Konagai, M. Shiozawa, N. Takenaka, H. Asano, H. Murakawa, K. Sugimoto, T. Nojima, H. Hayashida, H. Iikura, T. Sakai, and M. Matsubayashi, Nuclear Instruments and Methods in Physics Research Section A: Accelerators, Spectrometers, Detectors and Associated Equipment, 651, 268 (2011).

12. A. Schröder, K. Wippermann, T. Arlt, T. Sanders, T. Baumhöfer, N. Kardjilov, J. Mergel, W. Lehnert, D. Stolten, J. Banhart, and I. Manke, Int J Hydrogen Energ, 38, 2443 (2013).

13. M. A. Hickner, N. P. Siegel, K. S. Chen, D. S. Hussey, D. L. Jacobson, and M. Arif, Journal of The Electrochemical Society, 155, B427 (2008)

14. R. S. Fu, U. Pasaogullari, T. Shiomi, Y. Tabuchi, D. S. Hussey, and D. L. Jacobson, Journal of The Electrochemical Society, 159, F545 (2012).

15. P. Boillat, G. Frei, E. H. Lehmann, G. G. Scherer, and A. Wokaun, Electrochem Solid St, 13, B25 (2010).

16. P. Boillat and G. G. Scherer, in Handbook of PEM Fuel Cell Durability, H. Wang, X.Z. Yuan, and H. Li Editors, p. 255, Taylor \& Francis Group, LLC, CRC (2011).

17. R. Satija, D. L. Jacobson, M. Arif, and S. A. Werner, J Power Sources, 129, 238 (2004).

18. J. Park, X. Q. Li, D. Tran, T. Abdel-Baset, D. S. Hussey, D. L. Jacobson, and M. Arif, Int J Hydrogen Energ, 33, 3373 (2008).

19. J. P. Owejan, J. J. Gagliardo, S. R. Falta, and T. A. Trabold, Journal of the Electrochemical Society, 156, B1475 (2009).

20. K. Tajiri, C. Y. Wang, and Y. Tabuchi, Electrochim Acta, 53, 6337 (2008).

21. E. H. Lehmann, P. Vontobel, and L. Wiezel, Nondestructive Testing and Evaluation, 16, 191 (2001).

22. A. Iranzo, P. Boillat, and F. Rosa, Int J Hydrogen Energ, 39, 7089 (2014).

23. S. Litster, D. Sinton, and N. Djilali, J Power Sources, 154, 95 (2006). 